\title{
Zbigniew W. Sorbjan
}

\section{${\text { Lech } \text { Lobocki }^{1} \text { (D) . Sergej S. Zilitinkevich }}^{2,3,4,5}$}

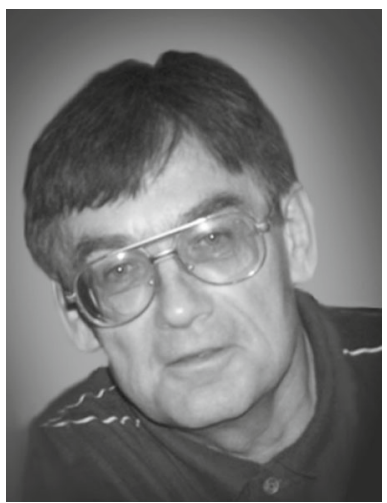

Zbigniew Wiesław Sorbjan, a renowned meteorologist and educator, passed away on February 19,2017 . He made a significant contribution to our understanding of atmospheric boundarylayer turbulence and dynamics, publishing more than 60 papers in leading journals. His textbook "Structure of the Atmospheric Boundary Layer" remains one of the most valued teaching aids in this field. In 1998, the popular "Hands-on Meteorology" won the JL Battan Author's Award of the American Meteorological Society, presented to authors of books that foster public understanding of meteorology. He taught at the Warsaw University of

Lech Łobocki

lech.lobocki@pw.edu.pl

1 Faculty of Building Services, Hydro and Environmental Engineering, Warsaw University of Technology, Warsaw, Poland

2 Finnish Meteorological Institute, Helsinki, Finland

3 Division of Atmospheric Sciences, University of Helsinki, Helsinki, Finland

4 Faculty of Geography, Moscow State University, Moscow, Russia

5 Institute of Geography, Russian Academy of Sciences, Moscow, Russia 
Technology, the University of Washington, the University of Wisconsin, the University of Oklahoma, Purdue University, and Marquette University. He also served as an associate editor of Acta Geophysica.

Zbigniew Sorbjan's scientific career began in 1969 at the Warsaw University of Technology, at a time of great advance of computing and numerical modelling into various fields of applied meteorology. At first, he was attracted by numerical weather prediction, which became one of his teaching courses and resulted in his first textbook "Basics of the Numerical Weather Forecasts" published in Polish in 1975. A few years later, he shifted his interest towards air pollution meteorology and boundary-layer meteorology, on which he focused his scientific activity throughout the rest of his life.

The 1970s was a fascinating period in boundary-layer research. During that time, analyses of field experiments such as Wangara and Kansas shed light on boundary-layer evolution and the structure of turbulence, large-eddy simulations were introduced, and Reynolds stress models paved their way from theory to application. Needless to say, in 1970 the Boundary-Layer Meteorology journal was born. Zbigniew Sorbjan had a chance to witness this fascinating explosion as a young scientist and soon joined the boundary-layer mainstream. In 1976, he obtained a doctoral degree for his thesis "Numerical Model of the Urban Boundary Layer Structure", then started to work on the monograph "Turbulence and Diffusion in the Lower Atmosphere" (in Polish), that appeared in print in 1983, three years after Sorbjan left Poland. As he recalled later, at that time he had become astonished with the ingenuity of the MoninObukhov similarity theory while working on this book, and this astonishment guided the rest of his scientific work.

The end of the 1970s brought growing difficulties to life and work in Poland, as the economy began to collapse and political tensions rose. In 1980, just before the eruption of crisis, Zbigniew obtained a postdoctoral fellowhip in Sweden, and moved to the U.S. soon after it. For his students at the Warsaw University of Technology in the 1970s, he will be remembered for his outstanding lectures on numerical weather prediction, turbulence and diffusion, boundary-layer dynamics, and numerical modelling.

Interestingly, Zbigniew Sorbjan became first known to the international boundary-layer community likely not for his publications, but rather for an incidental outcome of his artistic passion (Fig. 1). While participating in the milestone course "Atmospheric Turbulence and Air Pollution Modelling" in The Hague, September 1981, he drew caricatural portraits of lecturers, and these were included in the textbook of the course. The passion for arts, which also included painting and sculpting, accompanied him throughout his life. Zbigniew had deep and extensive knowledge in arts, literature and history, especially in the history of Poland in the context of European and World history. Notably, he researched his ancestors, who had originated from Armenia and came to Poland in the late middle ages. For the authors of this note, this made Zbigniew to some extent a personage of world history. For us and many of his friends, he was a brilliant guide around Warsaw and a very interesting person to talk to. His general culture revealed itself also in his scientific papers and books. Zbigniew had a vital gift for presenting deep concepts and complicated reasoning in an elegant and clear way, which made his style immediately recognizable. He was a bright person and an original thinker.

Sorbjan's papers published in the early 1980s dealt with the urban boundary layer and with the inclusion of terrain inclination effects into the Rossby-number similarity theory. In 1986, in his most-cited paper "On similarity in the atmospheric boundary layer" he extended Nieuwstadt's local similarity concept, and he focused on the stable boundary layer in a few subsequent works. Then, in the 1990s, he worked on the convective boundary layer and started applying large-eddy simulations in his studies, using a code he had written himself. 


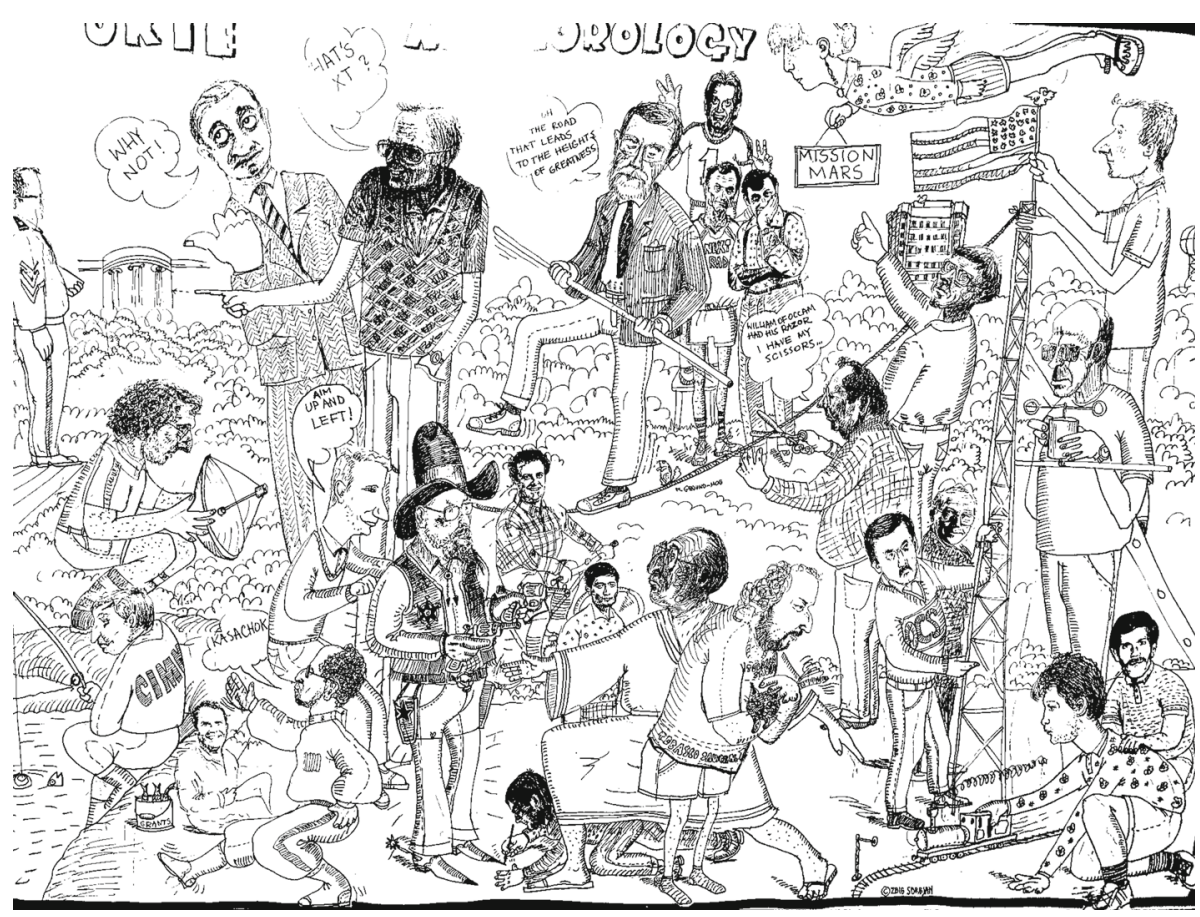

Fig. 1 One of Zbigniew's sketches, showing the faculty and associates of the School of Meteorology at the University of Oklahoma, Norman

He continued to use this tool throughout the next two decades, along with experimental data analysis, publishing a number of papers covering diverse topics in boundary-layer structure and turbulence, as well as on similarity theory. In 2008, he proposed a new system of scaling based on gradients rather than fluxes, the so-called gradient-based similarity, and for the rest of his life worked on the development of this theory. His last paper in this series, "Assessment of gradient-based similarity functions in the stable boundary layer", appeared in BoundaryLayer Meteorology in June 2017, four months after his death.

In the 1990s, after the political turnover in Poland, Zbigniew began to visit his homeland. In 1991, he obtained the second doctorate (habilitation) degree from the Institute of Geophysics of the Polish Academy of Sciences. Later on, he took up part-time employment at the Polish National Weather Service, and then at the Institute of Geophysics of the Polish Academy of Sciences, where he was working until the end of his life. In 2005, he was granted the highest Polish scientific rank-the professor's title. In 2014, he was also honored with the Stanislav Staszic Award of the Polish Academy of Sciences, for outstanding achievements that substantially contributed to the worldwide promotion of Polish science.

Open Access This article is distributed under the terms of the Creative Commons Attribution 4.0 International License (http://creativecommons.org/licenses/by/4.0/), which permits unrestricted use, distribution, and reproduction in any medium, provided you give appropriate credit to the original author(s) and the source, provide a link to the Creative Commons license, and indicate if changes were made. 